\title{
Transcatheter coil occlusion of residual interatrial communications after Fontan procedure
}

\author{
A Gamillscheg, A Beitzke, J I Stein, M Rupitz, G Zobel, B Rigler
}

\begin{abstract}
Objective-To assess the use of detachable coils as an alternative method to occlude interatrial communications after Fontan operations.

Design-Descriptive clinical study of selected patients after Fontan operation with interatrial communications inappropriate for transcatheter umbrella occlusion.
\end{abstract}

Setting-Tertiary paediatric cardiac referral centre.

Patients-Seven patients after Fontan operation with residual interatrial communications of various types producing a right to left shunt.

Interventions-Transcatheter placement of detachable coils with a diameter of 3 or $5 \mathrm{~mm}$ within the interatrial communication.

Results-A total of 14 coils were successfully placed within persistent patent fenestrations of the interatrial baffle, residual leaks at the suture line between the patch material and the right atrial wall, and unusual venous interatrial communications. The mean (SD) aortic oxygen saturation increased from $88(1.1) \%$ (range, $86-89 \%$ ) to $92(1.3) \%$ (range, $89-93 \%$; $\mathrm{p}<0.001$ ) and the mean (SD) right atrial pressure rose from 9.7 (2) $\mathrm{mm} \mathrm{Hg}$ (range, 6-11) to 10.6 (2.4) $\mathrm{mm} \mathrm{Hg}$ (range, 6-13; p < 0.05) after coil implantation. In five patients, complete obliteration of the interatrial shunt was shown by angiography after coil implantation. At a mean (SD) follow up of 10 (4) months (range, 3-15) a residual interatrial shunt was detected by Doppler colour echocardiography in only one patient, and oxygen saturations ranged from $90 \%$ to $95 \%$ (mean, 92\%). There were no late coil embolisations, thromboembolic events, or haemolysis in any patient.

Conclusions-Detachable coils can be used successfully to occlude residual interatrial communications after the Fontan procedure. In selected cases, in whom intended transcatheter umbrella occlusion of residual interatrial leaks is not possible, the use of detachable coils might offer a safe alternative method to eliminate interatrial right to left shunting after the Fontan procedure.

(Heart 1998;80:49-53)

Keywords: Fontan procedure; residual interatrial communication; coil occlusion
After modified Fontan procedures, persistent cyanosis caused by interatrial right to left shunts might be related to surgically created fenestrations of the interatrial baffle, ${ }^{12}$ to small residual leaks at the suture lines between the patch material and right atrial wall, ${ }^{1}$ or to unusual venous interatrial communications, which might evolve with the altered haemodynamics after the Fontan procedure. ${ }^{34}$ Intentionally created fenestrations of the interatrial baffle are usually closed either surgically ${ }^{5}$ or, more commonly, with transcatheter umbrella devices $^{1267}$ at various times after surgery. Multiple interatrial leaks, small size, or locations difficult to access might preclude closure with umbrella devices. In these selected cases, transcatheter occlusion with coils ${ }^{8}$ offers an alternative method to eliminate cyanosis and to reduce the increased risk of thromboembolic complications after Fontan procedures..$^{9-11}$ In this study, we present our experience with coil occlusion of residual interatrial communications after modified Fontan operations.

\section{Methods}

PATIENTS

At our unit, cardiac catheterisation is performed routinely one to three years after Fontan operations to evaluate postoperative haemodynamics and to check for residual interatrial defects and pulmonary artery distortions or other unsuspected lesions. Postoperative catheterisation was performed in 29 of 34 surviving patients who had undergone total cavopulmonary connection. In 12 patients, residual interatrial communications of various types were detected. In seven of these 12 patients, residual interatrial communications were considered inappropriate for intended occlusion with umbrella devices. The demographic data, diagnoses, and previous surgery of these seven patients are summarised in table 1. The patients had undergone surgery at a mean (SD) age of 3.8 (2.9) years. In five patients, the operation consisted of a total cavopulmonary connection using a Gore-tex intra-atrial baffle. ${ }^{12}$ In patient 4 , a left sided bidirectional Glenn anastomosis was performed and the hepatic venous blood was directed via the coronary sinus and a left sided superior caval vein to the left pulmonary artery. In patient 5 , the junction of the hepatic veins was connected via an intra-atrial tunnel to the superior caval vein and right pulmonary artery. In four patients with more than two preoperative risk factors, ${ }^{13}$ a fenestration of the interatrial baffle with a diameter of 3 to $4 \mathrm{~mm}$ was created using a coronary punch. After discharge, all patients were treated with oral 
Table 1 Major diagnoses, previous surgery, and age at total cavopulmonary connection

\begin{tabular}{lllll}
\hline & & & Age at \\
Patient/sex & Major diagnoses & Previous surgery & $\begin{array}{c}\text { TCPC } \\
\text { (years) }\end{array}$ & Fenestration \\
\hline 1/F & TGA, VSD, hypopl LV, PS & BT shunt & 3.9 & + \\
2/F & TA, TGA, VSD & PAB & 1.8 & - \\
3/M & DORV, hypopl LV, CoA & CoA op, PAB, BDGA & 3.6 & + \\
4/M & Polysplenia, S amb, DORV, AVC, LSVC, LIVC with V & PAB & 2.8 & + \\
& azygos continuity & & \\
5/F & Polysplenia, S amb, DORV, hypopl LV, & BT shunt & 10 & - \\
& IVC-interruption with V azygos continuity & CoA op, PAB, BDGA & 3.2 & - \\
7/F & TA, TGA, Co A & PAB, BT shunt & 1.5 & + \\
\hline
\end{tabular}

TCPC, total cavopulmonary connection; TGA, transposition of the great arteries; VSD, ventricular septal defect; hypopl LV, hypoplastic left ventricle; PS, pulmonary stenosis; TA, tricuspid atresia; DORV, double outlet right ventricle; CoA, coarctation aortae; S amb, Situs ambiguus; AVC, atrioventricular canal; LSVC, left sided superior caval vein; LIVC, left sided inferior caval vein; BT shunt, Blalock-Taussig shunt; PAB, pulmonary artery banding; CoA op, coarctation operation; BDGA, bidirectional Glenn anastomosis.

phenprocoumarol for a mean (SD) of 10 (2) months, followed by oral aspirin prophylaxis.

\section{PROCEDURES}

The study was approved by the local ethics committee. Informed parental consent was obtained in all cases before catheterisation and occlusion procedures. Indication for device closure was persistent or increasing arterial desaturation during follow up. The mean (SD) duration between surgery and transcatheter coil occlusion was 30 (22) months (range, 12-60). The mean (SD) age and body weight at the time of coil occlusion were 6.3 (4.1) years (range, 3.1-15) and 24.1 (15.7) $\mathrm{kg}$ (range, 13.7-58), respectively. One patient (patient 1) had undergone transcatheter occlusion of a fenestration with a $17 \mathrm{~mm}$ Rashkind double umbrella device 15 months before coil occlusion. At catheterisation, the patients were sedated with intravenous midazolam $(0.2 \mathrm{mg} /$ $\mathrm{kg}$ ) and ketamine $(2-4 \mathrm{mg} / \mathrm{kg}$ ) breathing room air. All patients received heparin (100 IU $/ \mathrm{kg}$ ) intravenously at the beginning of the catheterisation. Either the right femoral vein (five patients) or the right (patient 5) or left (patient
4) internal jugular vein were used for venous access, whereas the right femoral artery was used for arterial access in all patients. After complete haemodynamic assessment, including measurement of oxygen saturations, angiography of the systemic venous pathways, the pulmonary arteries, and the systemic ventricle were performed. Subsequently, an angiogram of the intra-atrial tunnel was obtained in the anterioposterior and lateral projections to localise more precisely and to estimate the size of residual interatrial leaks.

The method of coil delivery was based on current techniques of transcatheter occlusion of patent ductus arteriosus. ${ }^{14-17}$ Detachable coils (Wiliam Cook Europe, Bjaeverskov, Denmark) with a diameter of $3 \mathrm{~mm}$, producing four loops (MWCE-3 PDA 4), and $5 \mathrm{~mm}$, producing four or five loops (MWCE-5- PDA 4 and MWCE-5-PDA 5), were used in all patients. ${ }^{14-16}$ A 5 French endhole multipurpose or a 5 French right coronary catheter was advanced from the intra-atrial tunnel across the interatrial defect to the left atrium using a 0.035 inch guidewire (Terumo Europe NV, Leuven, Belgium). After adequate placement
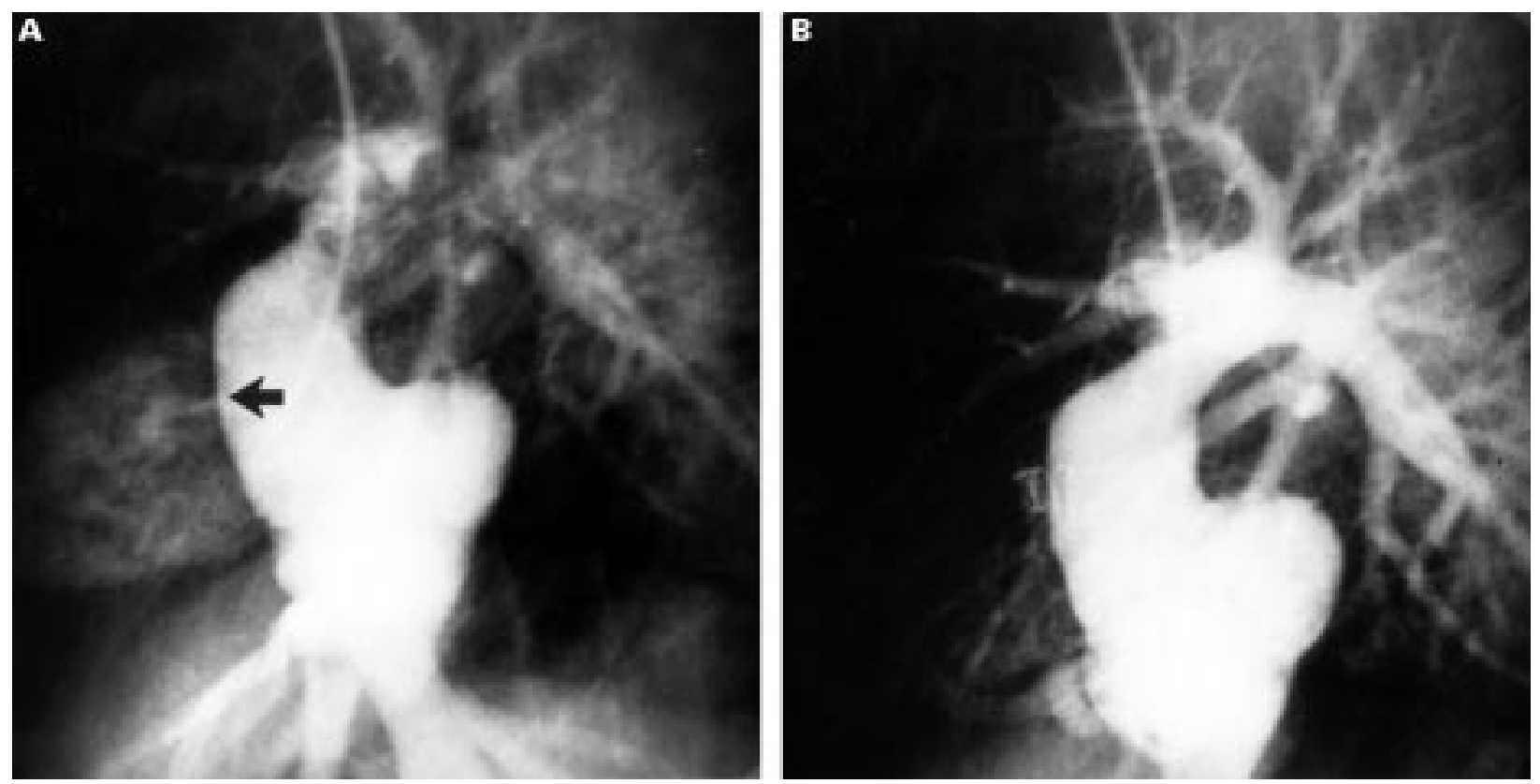

Figure 1 Angiogram of the intra-atrial tunnel of patient 4 (lateral view). (A) Small patent fenestration with right to left shunting indicated by arrow. (B) Successful occlusion with a coil. 

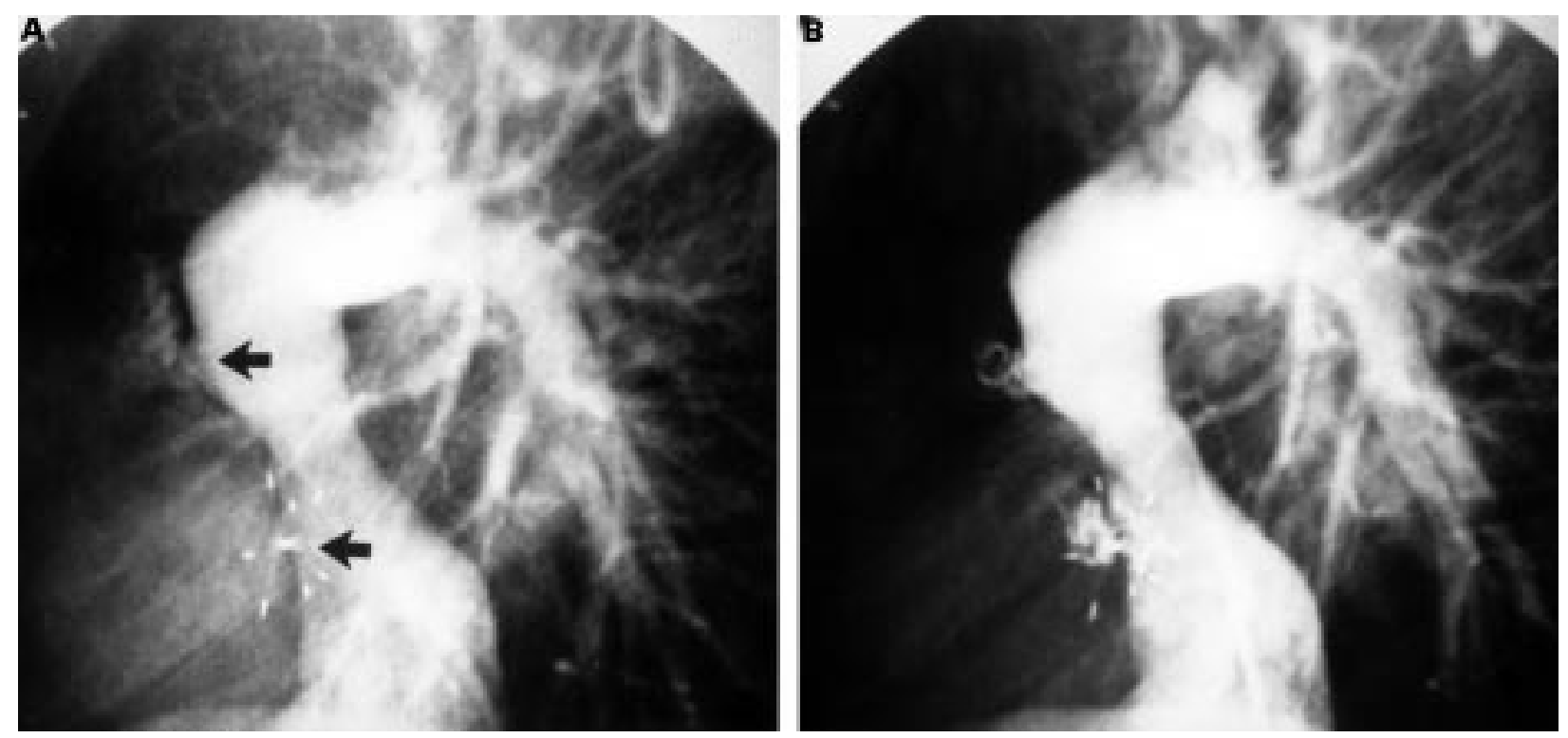

Figure 2 Angiogram of the intra-atrial tunnel of patient 1 (lateral view). (A) Residual leak at the fenestration after occlusion with a Rashkind umbrella and an additional interatrial venous communication draining into the left atrium (both indicated by arrows). (B) Successful coil occlusion of both the residual leak at the fenestration and the interatrial venous channel.

of the catheter, the coil connected to the delivery wire was inserted into the catheter and advanced into the pulmonary venous atrium to produce one to two loops. Subsequently, the catheter was withdrawn to produce the residual loops of the coil in the intra-atrial tunnel. When the catheter could not be passed through the interatrial leak, the catheter was wedged within the interatrial communication and the coil was delivered in this position. The procedure was monitored by transoesophageal echocardiography in three of the seven patients. Five minutes after detachment of the coil, angiography of the lateral tunnel was performed. If a significant residual or additional interatrial shunt was detected, further coils were implanted. After coil implantation, measurements of right atrial pressure and aortic oxygen saturation were repeated. The patients were discharged on oral aspirin prophylaxis ( $5 \mathrm{mg} / \mathrm{kg} /$ day).

FOLLOW UP

Follow up examinations included clinical evaluation, echocardiographic examination, chest $x$ ray, and measurement of oxygen saturation by pulse oximetry at day 1 , and three, and six months after the procedure.

DATA ANALYSIS

All data are expressed as mean (SD) and range. A two tailed paired Student's $t$ test was used for statistical analysis. $\mathrm{p}$ values $<0.05$ were considered significant.

\section{Results}

Three types of interatrial communications were identified angiographically (table 2). The first type presented as a small residual right to left shunt via the surgically created fenestration of the interatrial baffle (fig 1). Out of the four patients with fenestrations, the fenestration had closed spontaneously in one patient and one patient showed a residual leak after
Rashkind umbrella occlusion of the fenestration (fig 2). The second type of interatrial communication consisted of small venous channels at the superior portion of the interatrial baffle incorporating the pectinate muscle of the right atrium draining into the pulmonary venous atrium in three patients (fig 2). Two patients had right to left shunting at residual leaks of the suture line between the patch material and the right atrial wall separated from baffle fenestrations or interatrial venous communications.

Fourteen coils were positioned successfully within the interatrial communications. Before coil occlusion, the mean aortic oxygen saturation and the right atrial pressure were 88 (1.1)\% (range, 86-89\%) and 9.7 (2) $\mathrm{mm} \mathrm{Hg}$ (range, 6-11), respectively (table 2). After coil occlusion aortic oxygen saturation increased to 92 (1.3)\% (range, 89-93\%; p < 0.001) and right atrial pressure changed to 10.6 (2.4) $\mathrm{mm} \mathrm{Hg}$ (range, 6-13; p < 0.05; table 2). In five patients, complete occlusion of the interatrial shunt was shown by angiography of the intra-atrial tunnel immediately after coil implantation (figs 1 and 2), whereas a minimal residual leak persisted in two patients. In one patient (patient 5), arterial oxygen saturation remained unchanged because of the additional presence of intrapulmonary fistulas demonstrated with contrast echocardiography. No complications occurred during or immediately after coil implantation.

At a mean follow up of 10 (4) months (range, 3-15), all patients remained free from coil migration, thromboembolic events, or haemolysis based on clinical evaluation and laboratory investigations, respectively. Colour Doppler echocardiographic examinations revealed a minimal residual interatrial shunt in only one patient. Oxygen saturations measured by pulse oximetry ranged from $90 \%$ to $95 \%$ (mean, $92 \%)$. 
Table 2 Details of coil closure of residual interatrial communications after total cavopulmonary connection

\begin{tabular}{|c|c|c|c|c|c|c|c|c|}
\hline Patient & $\begin{array}{l}\text { Time } \\
\text { from } \\
\text { TCPC } \\
\text { to } \\
\text { occlusion } \\
\text { (months) }\end{array}$ & $\begin{array}{l}\text { Coil ( } \varnothing \\
m m / l o o p s)\end{array}$ & $\begin{array}{l}\mathrm{SaO}_{2} \\
(\%) \text { pre }\end{array}$ & $\begin{array}{l}\mathrm{SaO}_{2} \\
(\%) \text { post }\end{array}$ & $\begin{array}{l}\text { RAP } \\
\text { pre } \\
(m m \\
\mathrm{Hg})\end{array}$ & $\begin{array}{l}R A P \\
\text { post } \\
\text { (mm } \\
\mathrm{Hg})\end{array}$ & Type of interatrial communication & $\begin{array}{l}\text { Result of } \\
\text { coil closure } \\
\text { (angiography }\end{array}$ \\
\hline \multirow[t]{2}{*}{1} & \multirow[t]{2}{*}{39} & $1 \times 3 / 4$ & \multirow[t]{2}{*}{86} & \multirow[t]{2}{*}{92} & \multirow[t]{2}{*}{8} & \multirow[t]{2}{*}{9} & \multirow{2}{*}{$\begin{array}{l}\text { Residual leak after Rashkind umbrella } \\
\text { occlusion of fenestration, interatrial venous } \\
\text { communication }\end{array}$} & \multirow[t]{2}{*}{ Complete } \\
\hline & & $3 \times 5 / 5$ & & & & & & \\
\hline 2 & 15 & $\begin{array}{l}1 \times 5 / 5 \\
1 \times 3 / 4\end{array}$ & 87 & 92 & 11 & 11 & Interatrial venous communication & Complete \\
\hline 3 & 12 & $1 \times 5 / 4$ & 89 & 92 & 11 & 12 & $\begin{array}{l}\text { Spontaneous closure of fenestration, } \\
\text { interatrial venous communication }\end{array}$ & Complete \\
\hline 4 & 15 & $1 \times 5 / 5$ & 87 & 91 & 6 & 6 & Residual leak at fenestration & Partial \\
\hline 5 & 60 & $4 \times 5 / 4$ & 87 & 89 & 10 & 11 & Multiple defects at suture line & Complete ${ }^{\star}$ \\
\hline 6 & 12 & $1 \times 5 / 4$ & 88 & 92 & 11 & 12 & Residual defect at suture line & Partial \\
\hline 7 & 58 & $1 \times 5 / 4$ & 89 & 93 & 11 & 13 & Residual leak at fenestration & Complete \\
\hline
\end{tabular}

\section{Discussion}

Fenestration of the interatrial baffle has been shown to decrease postoperative morbidity and mortality in high risk patients undergoing total cavopulmonary connection. ${ }^{12}$ By creating an interatrial communication, an adequate cardiac output is maintained in the postoperative period at the expense of persisting cyanosis. Spontaneous reduction of the size or even closure of these intentionally created interatrial communications, ${ }^{18}$ particularly in cases of small fenestrations, ${ }^{19}$ have been reported. Small residual leaks at the suture lines between the interatrial baffle and the right atrial wall, ${ }^{1}$ as well as unusual interatrial venous communications evolving after Fontan operations, ${ }^{3}{ }^{4}$ might also produce a right to left shunt at the atrial level and persisting postoperative cyanosis. These interatrial venous communications originating from the left atrium and draining towards the right atrium might be normal small vessels not noted preoperatively despite appropriate investigation. ${ }^{3}$ With an increase in right atrial pressure after the Fontan procedure, these venous pathways might dilate, with reversal of flow to the lower pressure left atrium. As was seen in three of our patients, this type of interatrial communication is frequently located at the superior anterior portion of the interatrial baffle near the mouth of the right atrial appendage (fig 2). ${ }^{3}$ The predisposing factors for the development of these abnormal interatrial venous communications are still unknown.

Usually, elective closure of fenestrations of the interatrial baffle is achieved either surgically ${ }^{5}$ or, more commonly, with transcatheter umbrella devices ${ }^{1267}$ to restore a normal systemic arterial saturation. Multiple leaks, small size, difficult accessible locations, or the shape of residual interatrial communications can preclude closure with umbrella devices. As an alternative method, complete obliteration of residual interatrial communications by detachable coils, was demonstrated by angiography in five of our seven patients. On follow up, a persistent residual interatrial shunt was identified by colour Doppler echocardiography in only one patient. All patients showed a pronounced increase of oxygen saturation after coil implantation. However, in some patients who showed arterial oxygen saturations only around 90\% after device closure, possible causes of additional systemic venous shunting could not be excluded by our investigations. ${ }^{20}$ Successful transcatheter coil embolisation of various cardiovascular lesions, including fenestrations ${ }^{8}$ and other types of interatrial communications, ${ }^{3}$ after Fontan procedures has been reported previously. In contrast to other groups ${ }^{38}$ we used detachable coils. By using a controlled delivery system, the coils can be repositioned or removed before release if their position is suboptimal. ${ }^{14}$ Compared with the use of Gianturco coils, the risk of embolisation of the coil into the systemic venous system or the pulmonary venous atrium might be reduced. ${ }^{17}$ Because the coil is much smaller than umbrella devices, the risk of systemic or pulmonary venous obstruction, particularly in small patients, might be reduced. ${ }^{8}$

Because these small residual interatrial communications might cause only mild arterial desaturation, and the patients are frequently clinically well, the correct management of these patients remains controversial. ${ }^{21}$ Closure of large baffle fenestrations after modified Fontan procedures results in a reduction of cardiac index and tissue oxygen delivery secondary to the acute reduction of ventricular preload, ${ }^{22} 23$ which has led to the speculation that maintaining fenestration patency might be of haemodynamic benefit in some patients. ${ }^{23}$ However, the long term effects of persisting cyanosis on the development of paediatric patients have to be considered. Right to left shunt may increase with exertion, thereby inducing exercise intolerance.

Several reports have shown a significant incidence of thrombus formation within the systemic venous system and pulmonary arteries after Fontan procedures. ${ }^{9-112425}$ Leaving a patent interatrial communication with a right to left shunt increases the risk of systemic embolisation. Although these patients can be treated prophylactically with anticoagulants, the benefit and optimal duration of this treatment is still unknown. ${ }^{24}$ The thrombogenic surface of an occlusion device on the pulmonary venous side might induce systemic thromboembolism unrelated to right to left 
shunt, ${ }^{21}$ but the small size of a coil compared with umbrella devices may reduce this risk. ${ }^{8}$

In conclusion, this study demonstrates that coil occlusion of various types of residual interatrial communications after total cavopulmonary connection is technically feasible and offers an alternative method in patients in whom occlusion with umbrella devices is not possible.

1 Bridges ND, Lock JE, Castaneda AR. Baffle fenestrations with subsequent transcatheter closure. Modification of the Fontan operation for patients at increased risk. Circulation 1990;82:1681-9.

2 Kopf GS, Kleinman CS, Hijazi ZM, et al. Fenestrated Fontan operation with delayed transcatheter closure of atrial septal defect. Improved results in high-risk patients. I Thorac Cardiovasc Surg 1992;103:1039-48.

3 Huei-song H, Nykanen DG, Williams WG, et al. Right to left interatrial communications after the modified Fontan procedure: identification and management with transcatheter occlusion. Br Heart $\mathcal{7}$ 1995;74:548-52.

4 Hayes AM, Burrows PE, Benson LN. An unusual cause of cyanosis after the modified Fontan procedure-closure of venous communications between the coronary sinus and left atrium by transcatheter techniques. Cardiol Young 1994;4:172-4.

5 Kuhn MA, Jarmakani JM, Laks H, et al. Effect of late postoperative atrial septal defect closure on hemodynamic function in patients with a lateral tunnel Fontan procedure. f Am Coll Cardiol 1995;26:259-65.

6 Redington AN, Rigby ML. Novel uses of the Rashkind ducRedington AN, Rigby ML. Novel uses of the Rashkind ductal umbrella in adults and children
disease. Br Heart $71993 ; 69: 47-51$.

7 Redington AN, Rigby LM. Transcatheter closure of interatrial communications with a modified umbrella device. $B$ Heart f 1994;72:372-7.

8 Sommer RJ, Recto M, Golinko RJ, et al. Transcatheter coil occlusion of surgical fenestrations after Fontan operation. Circulation 1996;94:249-52.

9 Day RW, Boyer RS, Tait VF, et al. Factors associated with stroke following the Fontan procedure. Pediatr Cardiol 1995;16:270-5

10 Rosenthal DN, Friedman AH, Kleinman CS, et al. Thromboembolic complications after Fontan operations. Circulation 1995;92 (suppl II):II-287-93.

11 Kaulitz R, Ziemer G, Bergmann F, et al. Atrial thrombus after the Fontan-operation: predisposing factors, treatment and prophylaxis. Cardiol Young 1997;7:37-43.

12 de Leval MR, Kilner P, Gewillig M, et al. Total cavopulmonary connection: a logical alternative to atriopulmonary connection for complex Fontan operations. I Thorac Cardiovasc Surg 1988;96:682-95.

13 Choussat A, Fontan F, Besse P, et al. Selection criteria for Fontan's procedure. In: Anderson RH, Shinebourne EA, eds. Pediatric cardiology. Edingburgh: Churchill Livingstone, 1978:559-66.

14 Hazama K, Nakanishi T, Tsuji T, et al. Transcatheter occlusion of arterial duct with new detachable coils. Cardiol Young 1996;6:332-6.

15 Uzun O, Hancock S, Parsons JM, et al. Transcatheter occlusion of the arterial duct with Cook detachable coils: early experience. Heart 1996;76:269-73.

16 Tometzki AJP, Arnold R, Peart I, et al. Transcatheter occlusion of the patent ductus arteriosus with Cook detachable coils. Heart 1996;76:531-5.

17 Pauperio HM, Redington AN, Rigby ML. Closing the patent arterial duct-plugs, umbrellas and coils. Cardiol Young 1996;6:252-4

18 Kreutzer J, Lock JE, Jonas RA, et al. Transcatheter fenestration dilation and/or creation in postoperative Fontan patients. Am f Cardiol 1997;79:228-32.

19 Sherwood MC, Nunn GR, Sholler GF. Multiple small fenestrations created during construction of the total cavopulmonary circulation: subsequent course and spontaneous closure 7 Thorac Cardiovasc Surg 1996;112:553-4.

20 Gatzoulis MA, Shinebourne EA, Redington AN, et al. ncreasing cyanosis early after cavopulmonary connection caused by abnormal systemic venous channels. Br Heart $\mathcal{f}$ 1995;73:182-6.

21 Moore JW. Should Fontan fenestrations be closed with coils? Circulation 1996;94:247-8.

22 Mavroudis C, Zales VR, Backer CL, et al. Fenestrated Fontan with delayed catheter closure. Effects of volume loading and baffle fenestration on cardiac index and oxygen delivery. Circulation 1992;86(suppl II):II-85-92.

23 Hijazi ZM, Fahey JT, Kleinmann CS, et al. Hemodynamic evaluation before and after closure of fenestrated Fontan: an acute study of changes in oxygen delivery. Circulation an acute study of

24 Wilson DG, Wisheart JD, Stuart AG. Systemic thromboembolism leading to myocardial infarction and stroke after fenestrated total cavopulmonary connection. Br Heart $\mathcal{F}$ 1995;73:483-5

25 Beitzke A, Zobel G, Zenz W, et al. Catheter-directed thrombolysis with recombinant tissue plasminogen activator (rt-PA) for acute pulmonary embolism after Fontan operation. Pediatr Cardiol 1996;17:410-12. 